\title{
No Man's Land / Everyone's Land: Designing Processes for Enacting More-Than-Human Worlds. The Case of Bagnoli.
}

\author{
Gionata Gattoa, Alessia Cadamurob \\ aDubai Institute of Design and Innovation \\ 'Open University \\ *Corresponding author e-mail: gionata.gatto@didi.ac.ae
}

\begin{abstract}
:
This paper addresses the theme of brownfields, the actors, processes and materialities that constitute them, and the role design could play in re-defining their identities. The objective is to explore opportunities to deploy design to initiate a transformation of those places, through public engagement activities involving human and other-than-human agents. The work considers one case study, which involves a workshop with scientists, a brownfield on the outskirts of Naples (IT) and a geo-speculative account of its morphological settings. Building on the assumption that the site under question is culturally -not just materially contaminated, our argument is that other-than-human participation could provide more sustainable routes compared to traditional soil restoration methods. The results advance design opportunities for destabilizing the public perception of the site, suggesting at the same time an alternative notion of de-contamination, which consider the environment beyond technical lenses, accounting for the socio-cultural readings through which it is mediated to local communities.
\end{abstract}

Keywords: contamination; more-than-human; participatory speculative design; design activism

\section{Introduction}

\subsection{Brownfields as socio-technical environments}

The term 'brownfield' was originally used to describe areas -usually urban, that were previously subjected to development, as opposed to the term 'greenfield', which indicates land that has not been previously used (Alker et al., 2000). Since the transition to industrial economies until more recent post-industrial conditions, where industries abandoned production or moved to countries with lower labour costs, the number of brownfields across Europe kept multiplying. Simultaneously, uncontaminated land became increasingly scarce, forcing countries to develop policies of reuse for abandoned sites, most of which are now classified as post-industrial. A post-industrial brownfield 
consists of a delimited geographical area whose conversion is usually complicated by the presence of hazardous -at times toxic materials (EPA. US Environmental State Agency, 2009). The material configuration of those places is linked to the past history of abuse that affected their soil and manifests itself in the present through an arrangement of different material debris -most of which remains invisible to the naked eye.

The re-development of those sites usually involves practices of site preparation, studies on economic viability, development of legal policies and planning of future uses, all of which feature technological, economical, socio-cultural and environmental factors that are linked and interwoven (Grimski \& Ferber, 2001). As a matter of facts, the complex identity of those sites subjects them to preestablished cleaning protocols, especially in the case of areas contaminated by heavy metals. This includes processes of soil transformation, removal, immobilization, or mechanical excavation and treatment ex-situ (Zerbi \& Marchiol, 2004). Those practices, however, often result in economically unpractical investment projections, unless in the presence of real estate development plans, a path that formalizes the destiny of the majority of brownfields, which tend to remain unused unless designated to the construction industry (Haninger et al., 2012). Grimski and Ferber (2001) argue that the regeneration of post-industrial brownfields is complicated by several factors, that are:

the contradictory practice of permitting greenfield development whilst attempting to redress the serious environmental, economic and social problems associated with urban brownfields; the inflexibility of policy and legislation which inhibits the redevelopment of brownfield sites; insufficient information concerning the number and size of brownfields and of previously developed but now vacant buildings and sites in cities, and about the economic, social and environmental outcomes of redevelopment (Grimski \& Ferber, 2001)

From a sociological perspective, brownfields remain complex socio-technical environments, whose forms, processes and materialities are also interwoven to the public perception of risk. Soil pollution often produces blasted land, whose hazardousness has the effect of originating concerns (Grasmück \& Scholz, 2005) and biases related themselves to the public understanding of environmental contamination. As such, a polluted brownfield embodies processes and belongs to those sorts of places that rarely become actionable. Diversity in material and immaterial constitutions, and their public understandings, renders each contaminated site an idiosyncratic configuration of both human and nonhuman actors, whose identity is continually stabilized and destabilized by factors such as national soil restoration policies, the value lost or acquired in time by the land, and matter of concerns that become formed in time around each territory.

\subsection{A hyperaccumulator-eye view on contamination}

One possible way to depart from dichotomic readings of the land (e.g., pure/polluted, valuable/useless, safe/harmful) and began understanding the brownfield beyond socially constructed forms, is to try observing it from a more-than-human perspective. Among these, the one provided by hyperaccumulating flora acquires here a particular relevance. Hyperaccumulating plants are studied in the natural sciences for their ability at absorbing heavy metals from contaminated soil, and relocating those metals from the roots into the tissues, organs (Sauerbeck, 1991) and aboveground parts such as leaves (de Abreu et al., 2012). In the last decades, scholars in the environmental sciences began to explore possible applications of hyperaccumulators in the decontamination of brownfields. The metals absorbed from those plants can in fact be extracted, and harvested from the leaves, and burning the biomass, through a process known as Phytomining (Brooks et al., 1998). Depending on the considered species, several aspects can affect phytoextraction, such as the climate, type of environment, amount of contaminant available to the plant, and the multiple 
symbiotic interactions that become formed between hyperaccumulators, soil microorganisms such as bacteria and mycorrhizae (Souza et al., 2013) and even other plants and animals.

In the case of a brownfield affected by heavy metals, the ability of a species to colonize it depends on its capacity to evolve an ecotype that tolerate that very configuration of heavy metals (Bert et al., 2000). Previous research suggests this to be a physiological mechanism enacted from the plant as a form of self-defence from external agents (Hörger et al., 2013). This feature renders the process of metal uptake an expression of vegetal agency.

Jones and Cloke (2008) argue that there are four ways in which trees can be regarded as having significant agency:

1) routine actions: a plant's biological processes, such as growth, reproduction, fructification, spread, etc;

2) transformative actions: a plant's way of creating new directions, formations and fields of relations, which ultimately lead to the transformation of a place;

3) purposive action: a plant's capacity of executing the instructions inscribed in its DNA, thus influencing future courses of action;

4) non-reflexive action: a plant's capacity to engender affective and emotional responses from the people who dwell amongst it. (Jones \& Cloke, 2008)

According to Jones and Cloke (2008), those four action modes can be used to account for the ways in which plants influence social life. Previous research, for instance, showed that hyperaccumulators can act transformatively and purposively on their territory, operating as 'witnesses' of the history of human transitions on the land (Gatto, 2017). Jones and Cloke (2008) argue that it is from the "treeplace" that we can experience how plants co-construct processes and social relationships in collaboration with other agents, across time and space (Jones \& Cloke, 2002, 2008).

\section{Materials and Methods}

\subsection{Introduction and Research Participants}

The research presented in this paper was initiated in October 2018 and took the form of a residency that lasted for two months, on occasion of the project: Art Meets Science (Wageningen University \& Research, 2018) a trans-disciplinary initiative promoted from the University of Wageningen (WUR). Our investigation involved a collaboration between two designers (the authors of this work), two biologists from the Environmental Sciences group, and two social scientists, with whom we explored ways to "harness evolutionary processes to increase resilience in the face of accelerating global change" (Ibid). The team was formed in situ, after a series of interviews with scholars in the natural sciences, with whom we discussed topics and possible directions for design work. The methods used during the residency involved workshops with the team members, oriented to explore the topic and some instances of contaminated sites, and geo-speculative approaches finalised to anticipate the morphological settings of those areas, in view of plausible future interventions.

\subsection{Workshop with Scientists}

The residency at WUR orbited around two interconnected themes: that of soil pollution, seen from the perspective of other-than-human hyperaccumulators, and that of public engagement with contaminated sites, given that local human communities witness the development of nearby brownfields over time. During the residency, we organised a series of workshops, where we asked in 
what ways a contaminated site could open to alternative modes of human/plant interaction, and whether this could lead to multispecies forms of resilience and inhabitation of those places. Our interest was to explore if the blasted landscape could by any means become enacted, owned back by local communities, and whether a subversion of established power relations could lead to encounters between people and plants that could socially reassemble those territories.

For the two organised workshops (Figure 1a,b,c,d), we set to explore how hyperaccumulators might be engaged as active participants in the negotiation of new forms of interaction between human communities and territories affected by heavy metals. Considering plants alongside humans as participants in the design process was meant to open opportunities for discussing equality in participatory rights, an issue at the core of the debate of the participatory design movement (Rice, 2017). Multispecies Design (Gatto, 2019; Gatto \& McCardle, 2019) was considered as an approach that could help us engaging with plants, exploring their viewpoints as an opportunity for designing participatory more-than-human worlds. Within this methodological framework, we considered posthuman tactics that could help us engaging both, human and vegetal actors. The aim here was not about achieving perfect translations, but to ask instead 'what matters' to nonhumans (Bastian, 2017) and attempt to understand "who benefits, qui bono, when species meet?" (Kirksey et al., 2014).

One of the workshops took the format of a transdisciplinary conversation between the team members. The activity had two main objectives. The first was to co-investigate possible modes of restoration for polluted territories through the active participation of hyperaccumulators. The second was to co-generate ideas and new knowledge with scientists, using scenarios as a way of speculating about possible futures for post-industrial landscapes (Figure 01d).
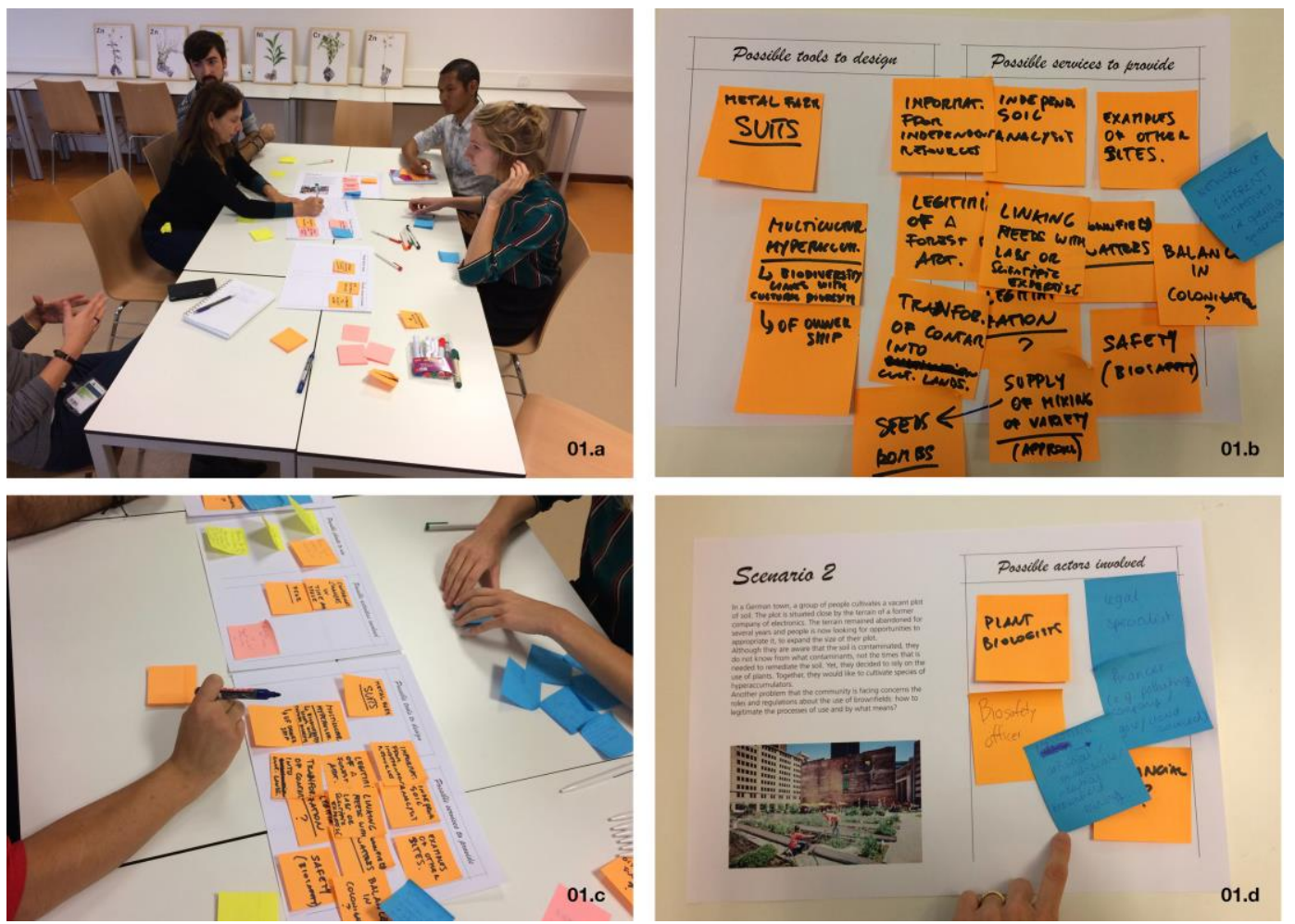

Figure 1. Phases of the first workshop at WUR, involving two designers, one environmental scientist, one plant scientist and two social scientists.

The activities were mediated by speculative scenarios and storytelling that involved three material contaminations: that of soil, air and water. Those triggered and motivated an in-depth discussion 
between the participants, providing at the same time relevant insights. Together, we conceptualized possibilities for a participatory design process involving hyperaccumulators, oriented to facilitate an expression of their agentic forces. This opened up three important themes: the first, being about ways to achieve an active participation of hyperaccumulators, including their role and positionality within the project; the second, more concerned with an understanding of the power relations and dynamics that could emerge from an active participation of plants into the final design. The third theme opened up the topic of legitimisations of polluted territories colonised by hyperaccumulators and led us to consider what possible networks could emerge due to the use of activism as a public engagement method. This involved, for instance, activities of seed sowing, to be performed on private polluted territories. By digging into the complexities intrinsic in such interventions, the workshops provided important outputs, indicating alternatives and possible routes for intervening on those sites, which are further addressed in the discussion chapter.

\subsection{Site of Bagnoli: processes, materialities and matter of concern.}

During the residency, we explored possible territories to be considered for future interventions. One of those is the Bagnoli-Coroglio brownfield, a delimited area situated on the outskirts of Naples, in Italy. During the last century, the site hosted the infrastructures of companies such as ILVA, Eternit, Cementir and Federconsorzi, constituting the second largest national site dedicated to steel processing. After the cease of industrial activities in 1991, the territory remained heavily polluted, as a result of insufficient policies forcing previous industries to decontaminate the soil. At these days, the site's soil is populated by multiple material entities, which differ in terms of amount, scale, physical state, but also origin, featuring heavy metals such as Vanadium, Copper, Arsenic, Thallium, Zinc, Lead, and Cadmium (Guarino et al., 2019). Such assemblage of chemical elements, coupled with climate conditions, state of the soil, and introduction of cultivated plants, enabled the emergence of a vegetal network that currently include several families and species (Table 1).

Table 1. Endemic families and species previously found on the site of Bagnoli-Codoglio (Guarino et al., 2019).

\begin{tabular}{ll}
\hline Family & Species \\
\hline Fabaceae & Bituminosa bituminosa \\
& Lotus corniculatus \\
\hline Asteraceae & Dittrichia viscosa \\
& Artemisia vulgaris \\
& Senecio vulgaris \\
\hline Poceae & Festuca arundinacea \\
& Piptatherum miliaceum \\
\hline Scrophulariaceae & Phragmites australis \\
\hline Apiaceae & Verbascum sinuatum \\
\hline Salicaceae & Helichrysum litoreum \\
\hline Plantaginaceae & Ferula communis \\
\hline Brassicaceae & Populus alba \\
\hline
\end{tabular}


Some of those plants are classified as accumulator, others as metal-tolerant or excluders. For instance, the species Brassica, from the Brassicaceae family (Figure 2), is described as an accumulator of Cadmium, Zinc and Lead, all of which are metals found -in different percentages, inside the site of Bagnoli.

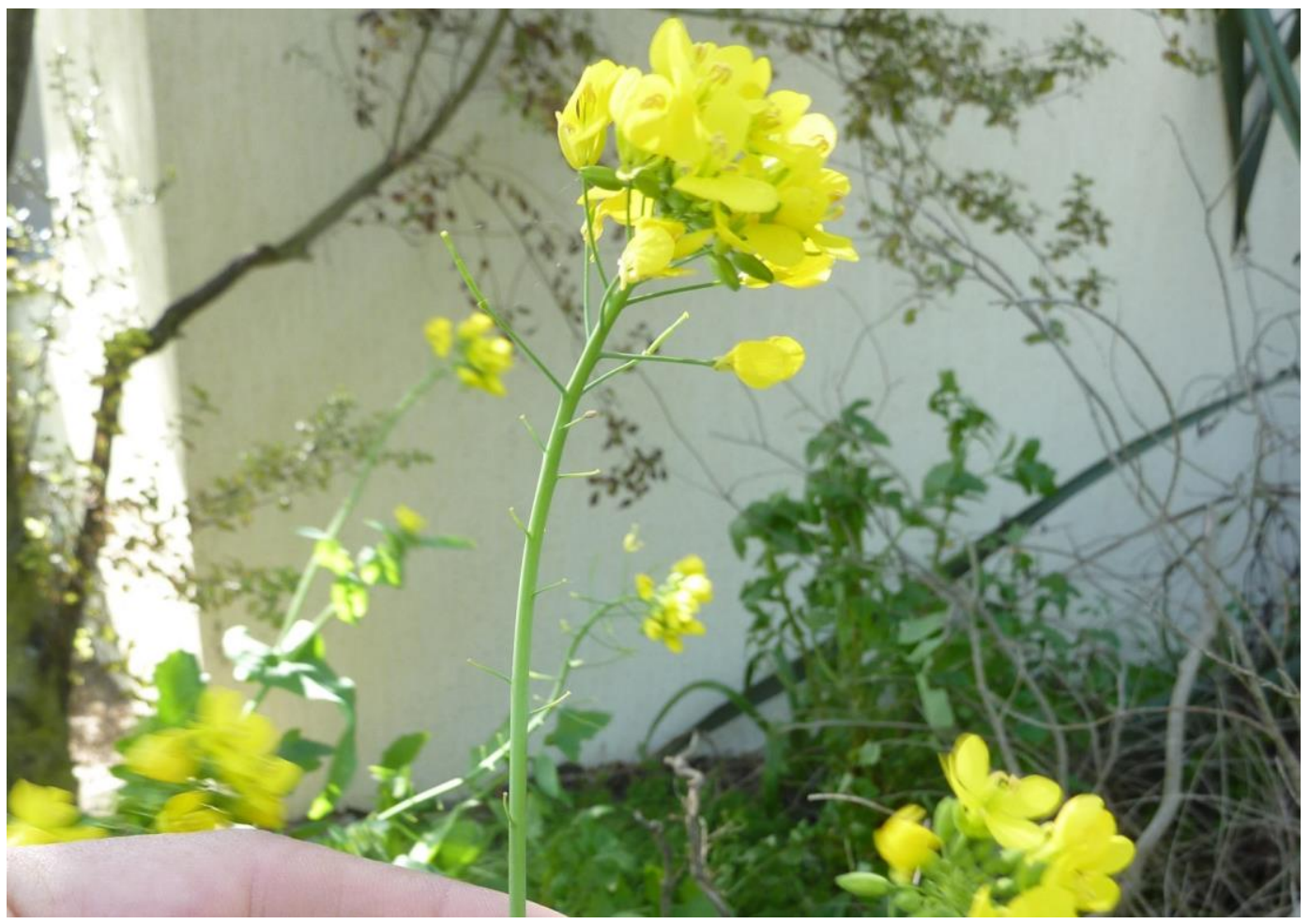

Figure 2: Sample of the metal-tolerant species Brassica, showing the inflorescence with yellow buds

One interesting feature of the site concerns the origins of its debris. The area was initially expected to be saturated by heavy metals due to the combustion of fossil fuels and disposal of industrial waste, however recent research demonstrates that it is also affected by the material effects of hydrothermal activity, originated from the adjacent volcanic caldera of Campi Flegrei (De Vivo \& Lima, 2008). This imbroglio of geological and anthropogenic factors is just one of the causes that complicates the requalification of the brownfield.

For twenty-five years, the site has been made impenetrable by the Italian government, with a wall being built along the perimeter to prevent unauthorized entries. The political forces that governed Naple in the past years did not provide viable solutions nor continuity in terms of remediation policies. Recently, citizens from communities living in proximity of the site began aggregating into collectives, such as the organisations Bagnoli Libera and Osservatorio Popolare di Bagnoli, founded in 2019. Their direct engagement through independent surveillance actions of the lot, led to unveil illegal activities being conducted on the site, such as the stockage of unauthorised urban waste from the city of Naples and neighbouring towns. Although legal actions were initiated to address those issues, including the formation of a parliamentary inquiry commission that led to a comprehensive report and the assessment of responsibilities for perpetuated environmental crimes, the site is still far from witnessing a structural regeneration nor a consolidation of adequate policies of social and environmental justice. 
Continuous public requests led, in 2020 , to the beginning of practices of site remediation, even though associations of citizens demanded for more incisive roles in controlling, regulating and witnessing the socio-ethical effects of such interventions. Members from citizens' collectives began trespassing the site's wall to directly access the area for self-monitoring the actual conditions of the land. Those practices of activism -followed by petitions, keep being implemented, as a way of triggering positive changes for the community who lives around Bagnoli. In this sense, public activism can be read as a political act, where the term 'political' refers to "a wider view of the citizen contributing to a broad political dialogues within society, where the question being asked is "in what sort of society do we want to live?"(Fuad-Luke, 2009, p. 6). Communities of citizens, in Bagnoli, have been moving towards a self-empowerment, as a way of coping with concerns that directly affect their houses, schools, living spaces. For them, Bagnoli is not just matter of concern, but a public asset that must be owned back from the inhabitants and protected through collective participatiory actions.

\subsection{Geo-anticipation and geo-speculation}

Exploring restricted sites, such as that of Bagnoli, presents several dilemmas: how to properly understand the current state of the area, the distribution of vegetation, and its relationship with manmade infrastructures? Geo-speculation (Gabrys, 2016, p. 139; Gatto, 2017) was used in this project as an approach to gather a geographical understanding of the site and at the same time script possible paths to design our interactions with the territory. Gabrys (2017) defines "geo-speculation" as a series of explorative practices oriented to anticipate and identifying formations of invisible environmental debris (Ibid). Doing that involves thick descriptions of the territory, based on previous research and the use of geographical information programs, such as GoogleEarth, which provides GPS- supported aerial views of the area. The program features functions such as that of map overlay, which allows to superimpose thematic maps into one single visualization. In this case, the support of GoogleEarth combined with the process of map overlay revealed that most of Bagnoli's former industrial apparatus returned to be entangled with multiple types of vegetation (Figure 3), and that its current morphology still reveals part of its former functional settings. The information collected through the process provided inputs for a design intervention, which we describe in the following chapter. 


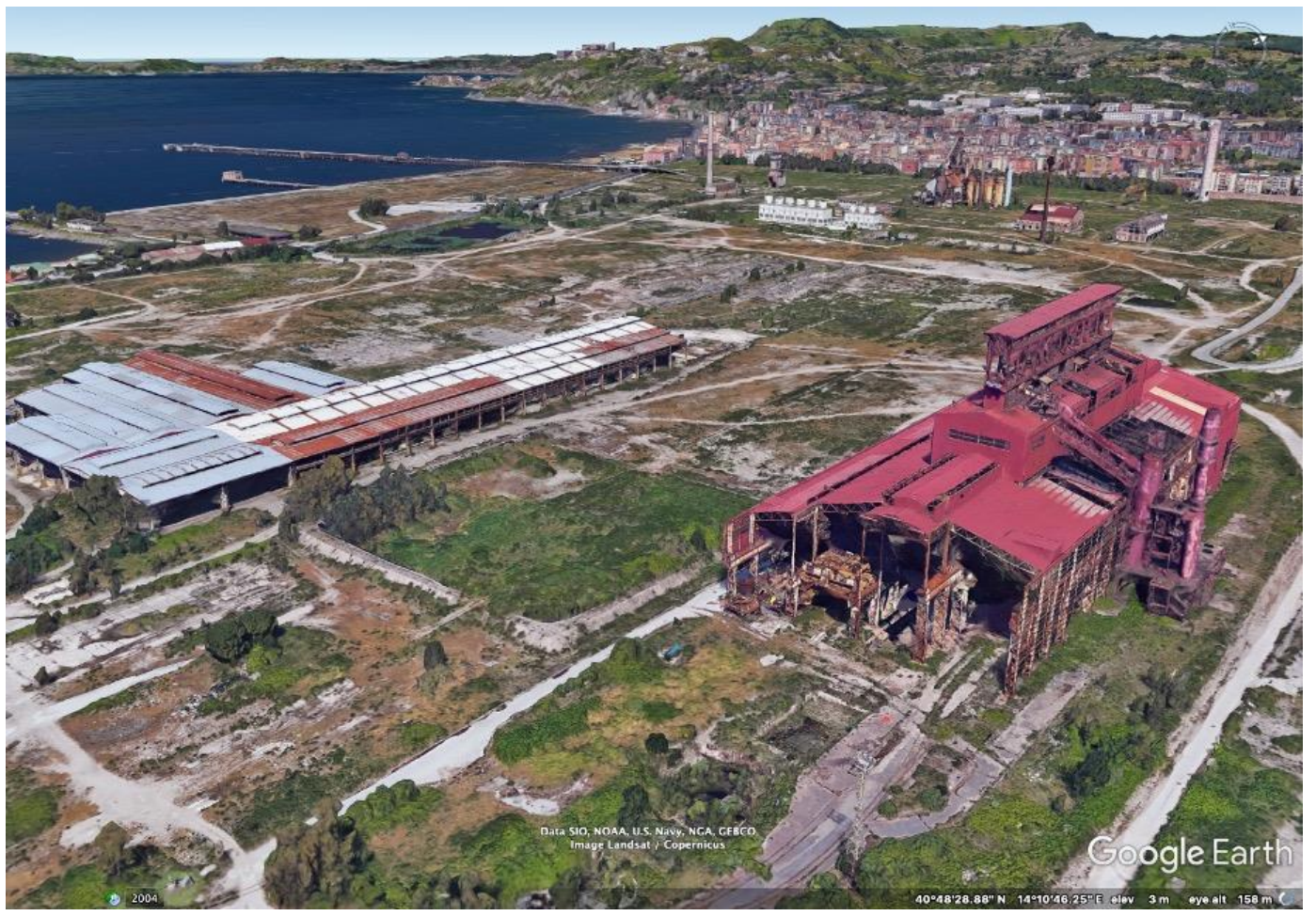

Figure 3. GoogleEarth view of the brownfield site of Bagnoli-Coroglio, Naple, Italy. The photo highlights areas covered in vegetation, juxtaposed to manmade infrastructures such as white roads, the former industrial apparatus and associated areas, used in the past for steel working.

\section{Results and Discussion}

\subsection{Design as Enacting and Legitimising a Multispecies network}

The methodological configuration and activities described in chapter 2 provided inputs and information that led us to design the foundation for the ongoing project Vegetal Rescuers, one of the main outcomes of this research. The project consists of two interconnected design elements. The first is the website vegetalrescuers.org, whose aim is to connect situated ecological and environmental knowledges about hyperaccumulators, providing at the same time opportunities to understand what plants might participate in experiments within different ecosystems, according to criteria of endemicity. The website is conceptualized as a trigger for environmental and social engagement, in that it represents a way for human communities to better understand the ecology of near-by contaminated sites. For instance, one of the results from the interdisciplinary workshops highlighted the need to inform citizens about the environmental conditions of specific areas, providing information concerning the type of plants that grows, or could potentially grow on a contaminated site. Hence, the website features a function of "plant finding", which allows users to select the mode of environmental contamination they wish to explore (Fig. 4), and then input data concerning the location of the area (Figure 5). The tool is designed to run a search within a growing database of hyperaccumulating flora, suggesting three species that can grow and prosper well on that land. 


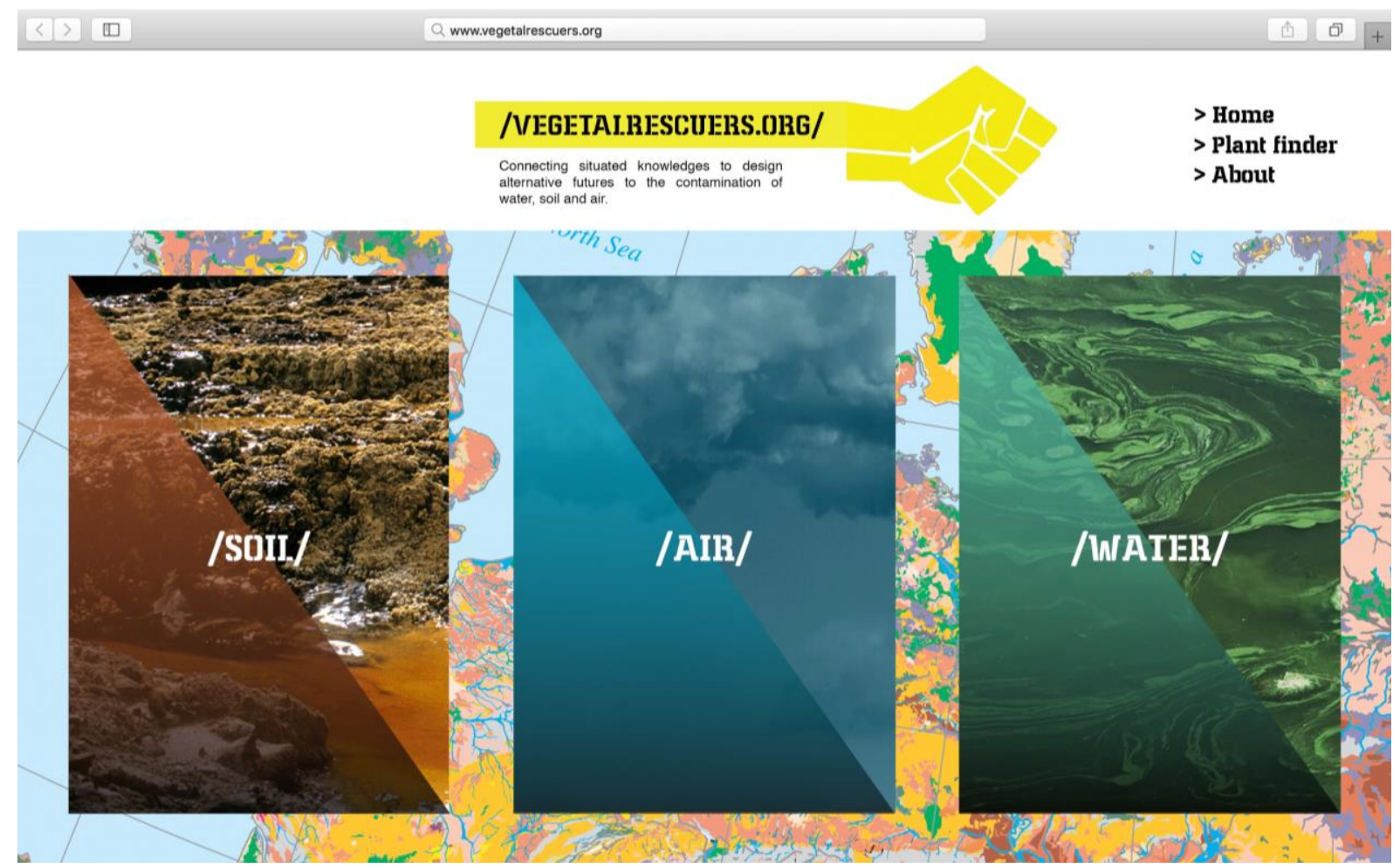

Figure 4: Plant Finder section of the website VegetalRescuers.org

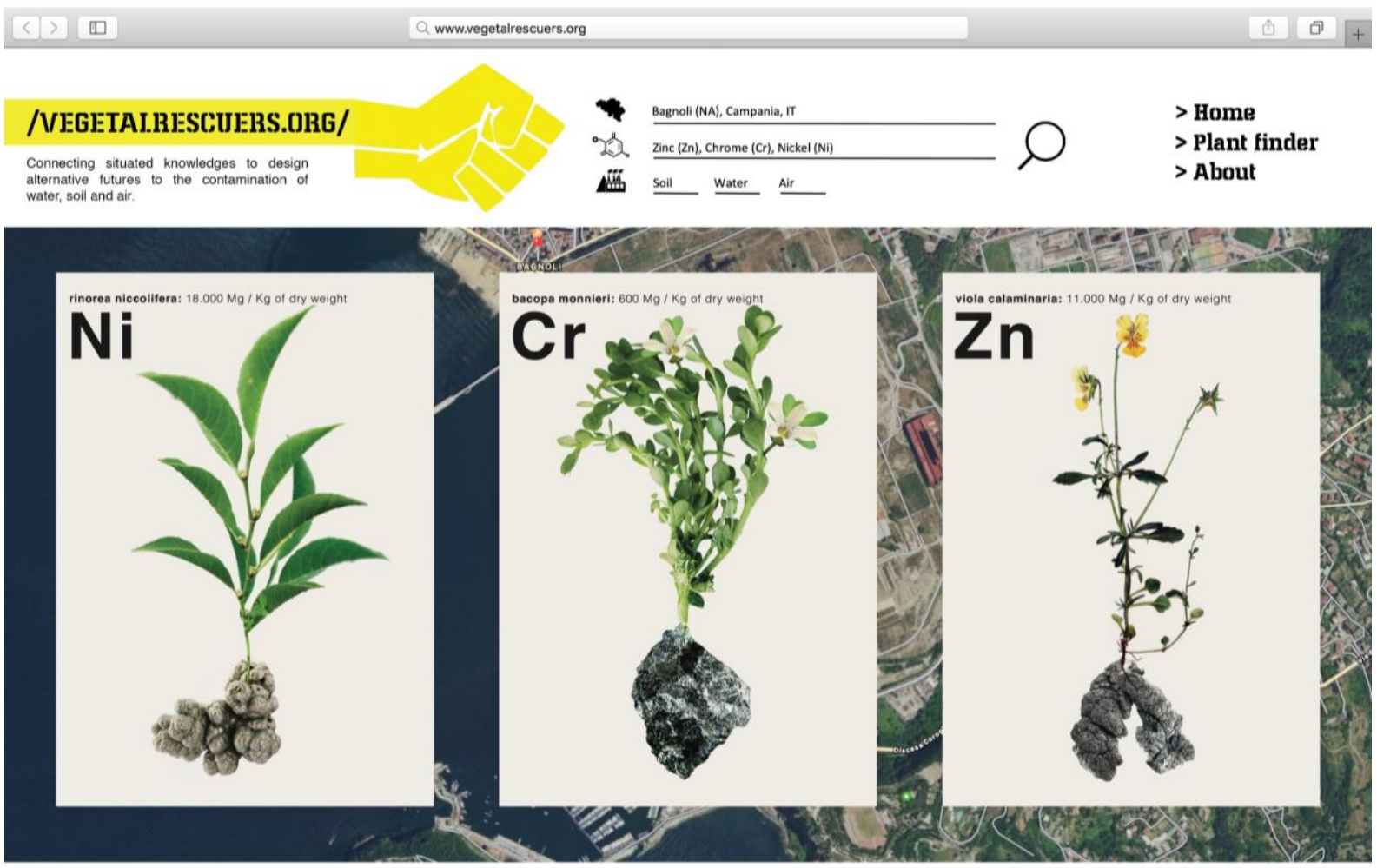

Figure 5: Plant Finder representation of plants that could grow on a specific site, considering it's climate and environmental conditions, extracted from the website VegetalRescuers.org

The second element of the project consists of a proposition for site-specific interventions on polluted sites, in this case, the brownfield of Bagnoli-Codoglio. Previous research shows that the site features a contaminated area that is geographically extended and not easily accessible due to limitations in place to prevent unauthorized entries. To cover the vastness of the site, the project foresaw the use 
of a drone, pre-programmed to follow specific air-paths. By adding a specially designed sawing module to the drone, the device would operate as a plant- printer, hence the possibility of sprinkling seeds even in areas that are -by default, inaccessible. While expressing their routing and purposive actions -that is, growing, prolificating, and executing their own genetic instructions as accumulating flora, the scattered seeds would slowly transform the land into a site for multispecies action. The process is designed to support and reinforce the presence of endemic hyperaccumulators and their modes of agency, providing a blank canvas for the growth of a vegetal artwork (Figure 6).
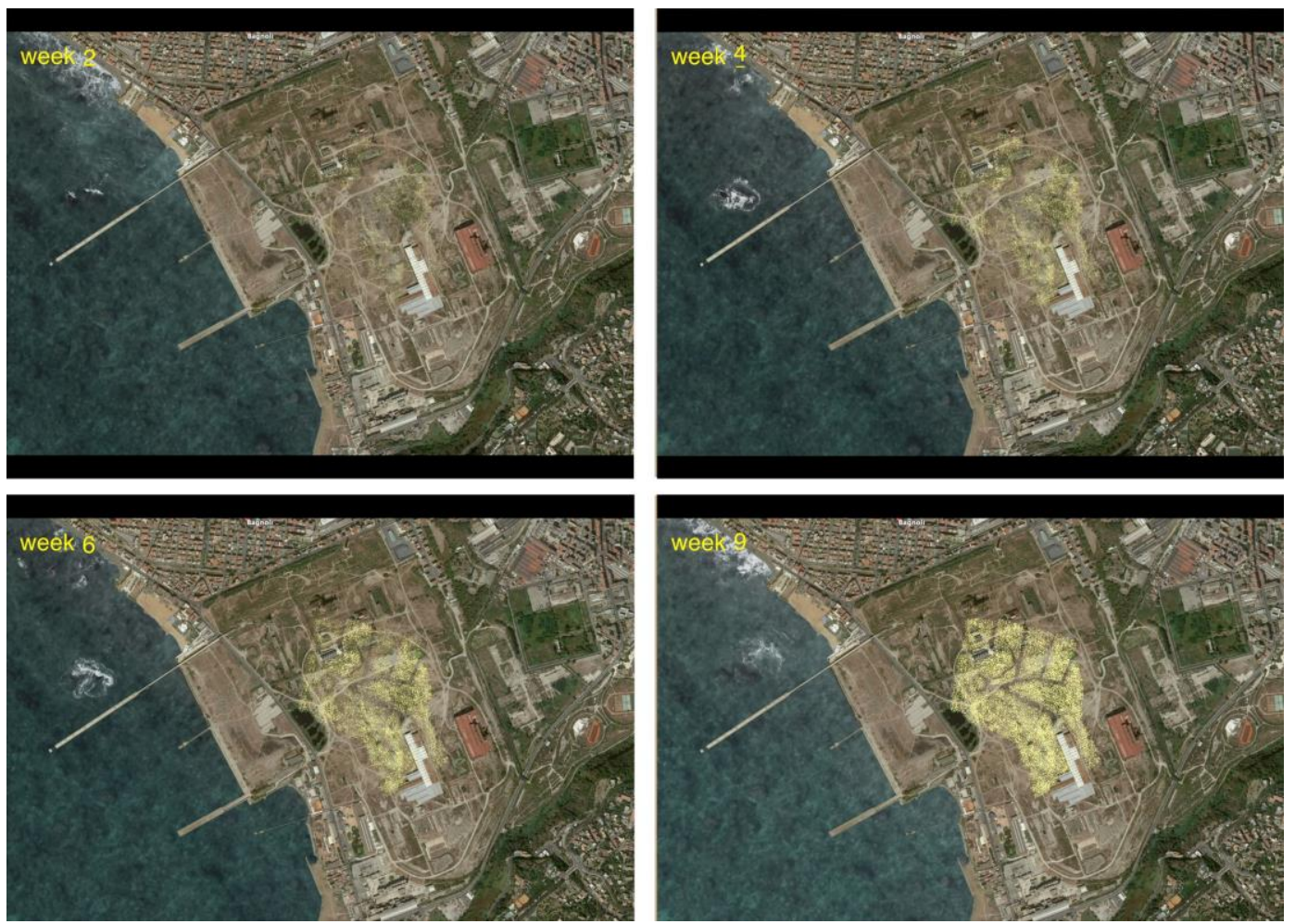

Figure 6: Representation of the vegetal artwork foreseen to be printed on the site of Bagnoli (Italy). Pictures are extracted from a video prepared on occasion of the project launch

The aim here is to employ seeds as a way of legitimizing public use and access to the site, thanks to the re-qualification of the area as an emergent site of environmental, cultural, and artistic interest for the community. Multispecies participation could become a way to negotiate new uses and forms of commoning (Hillgren et al., 2016) for the site of Bagnoli-Codoglio. It could, for instance, open to new roles for plants as environmental and cultural agents in an emergent more-than-human network, consolidating novel modes of affect and human-plant relationships. On a speculative level, this could led to re-interpret the site as legal-entity, legitimized by the existence of such relationship and expressions of care that Bagnoli's inhabitants have already been expressing towards their territory. The question of whether this could -or not, become a viable route remains open, however, recent events remind us that it is possible. In New Zealand, for instance, the Whanganui river has recently become an actual "legal person" (Evans, 2020), obtaining the same rights as a human being. This, thanks to the resilience and fights-for-rights of the Māori tribe who inhabits that land, who claimed its recognition as "ancestor" (Forlano, 2017).

No need to say, the New Zealand government nowadays treats "crimes against the river as crimes against the tribe" (Ibid). 


\section{Conclusion}

In this paper, we discussed an exploratory journey that led us to anticipate opportunities of multispecies design to be enacted in the contaminated brownfield of Bagnoli, through a synergistic interaction between human communities (including the design team, scientists and activists) and hyperaccumulator plants. The literature survey and methodological approach shed light on the intrinsic complexity of the concept of brownfield, not just from an environmental, but also from a social and cultural viewpoint. As technical solutions might provide quick, although expensive fix to the issue of soil pollution, we contended that a 'contamination' also heavily affects the public perception of those areas, hence it should call for interventions that consider a multiplicity of environmental, technological, and socio-cultural practices oriented to a re-integration of the sites as community assets.

We also discussed 'agency' as a relational concept that provides an understanding of plants as participant actors who can frame the social, and presented the design process as a performative continuum of human and vegetal acts. Engaging with those concepts, we suggest, could open to design opportunities for legitimating the contaminated site, as a result of the plants' ability to perform routine, purposive, and transformative processes on the territory.

The presented work wishes to support an inversion of thought concerning problematic environmental concepts. Although the presented project is still ongoing and -at the time of writing, only partially implemented, some first methodological reflection and conclusions can be drawn. We argue that approaches building on multispecies theory and involving transdisciplinary practices such as workshops and geo-speculative explorations, can be used to anticipate plausible environmental and social developments of post-industrial sites, accounting for the different, multiple perspectives that determine the perception of those places. In the case of the project presented in this work, this became possible through an extensive trans-disciplinary literature survey, interactions with scientists and field practitioners that considered both environmental and speculative readings of the site, the support of GIS systems and techniques of map overlay that allowed to virtually access an otherwise inaccessible land.

It is our hope that the work will open opportunities for future practices of design activism on problematic land, opening to the involvement of multispecies, participatory, and speculative approaches as a way of begin disentangling their complexity.

\section{References}

Alker, S., Joy, V., Roberts, P., \& Smith, N. (2000). The definition of brownfield. Journal of Environmental Planning and Management, 43(1), 49-69. https://doi.org/10.1080/09640560010766

Bastian, M. (2017). Towards a more-than-human participatory research. In O. Jones, N. Moore, \& E. Roe (Eds.), Participatory Research in More-than-Human Worlds (pp. 19-37). Routledge. https://doi.org/10.4324/9781315661698

Bert, V., Macnair, M. R., De Laguerie, P., Saumitou-Laprade, P., \& Petit, D. (2000). Zinc tolerance and accumulation in metallicolous and nonmetallicolous populations of Arabidopsis halleri (Brassicaceae). New Phytologist, 146(2), 225-233. https://doi.org/10.1046/j.14698137.2000.00634.x

Brooks, R. R., Chambers, M. F., Nicks, L. J., \& Robinson, B. H. (1998). Phytomining. In Trends in Plant Science (Vol. 3, Issue 9, pp. 359-362). https://doi.org/10.1016/S1360-1385(98)01283-7

de Abreu, C. A., Coscione, A. R., Pires, A. M., \& Paz-Ferreiro, J. (2012). Phytoremediation of a soil contaminated by heavy metals and boron using castor oil plants and organic matter 
amendments. Journal of Geochemical Exploration, 123, 3-7.

https://doi.org/10.1016/j.gexplo.2012.04.013

De Vivo, B., \& Lima, A. (2008). Characterization and Remediation of a Brownfield Site.: The Bagnoli Case in Italy. In Environmental Geochemistry. Elsevier B.V. https://doi.org/10.1016/B978-0-44453159-9.00015-2

EPA. US Environmental State Agency. (2009). Brownfields. http://www.epa.gov/oswer/international/factsheets/200906_eu_soils_contamination.htm

Evans, K. (2020). The New Zealand river that became a legal person. BBC. http://www.bbc.com/travel/story/20200319-the-new-zealand-river-that-became-a-legalperson

Forlano, L. (2017). Posthumanism and Design. She Ji: The Journal of Design, Economics, and Innovation, 3(1), 16-29. https://doi.org/10.1016/j.sheji.2017.08.001

Fuad-Luke, A. (2009). Design Activism. Beautiful Strangeness for a Sustainable World. Earthscan from Routledge.

Gabrys, J. (2016). Program Earth. Environmental Sensing Technology and the Making of a Computational Planet. University of Minnesota Press.

Gatto, G. (2017). Geo-Speculating with a Hyperaccumulator : A Former Mine in North-Rhein Westfalia from the Viewpoint of Arabidopsis Halleri. 6th STS Italia Conference. Sociotechnical Environments.

Gatto, G. (2019). Design as Multispecies Encounter: Plant Participation and Agency In and Through Speculative Design. Loughborough University.

Gatto, G., \& McCardle, J. R. (2019). Multispecies Design and Ethnographic Practice : Following OtherThan-Humans as a Mode of Exploring Environmental Issues. Sustainability, 11.

Grimski, D., \& Ferber, U. (2001). Urban brownfields in Europe. Land Contamination and Reclamation, 9(1), 143-148.

Guarino, C., Zuzolo, D., Marziano, M., Baiamonte, G., Morra, L., Benotti, D., Gresia, D., Stacul, E. R., Cicchella, D., \& Sciarrillo, R. (2019). Identification of native-metal tolerant plant species in situ: Environmental implications and functional traits. Science of the Total Environment, 650, 31563167. https://doi.org/10.1016/j.scitotenv.2018.09.343

Haninger, K., Ma, L., \& Timmins, C. (2012). Estimating the Impacts of Brownfield Remediation on Housing Property Values. Duke University Press Books.

Hillgren, P.-A., Seravalli, A., \& Eriksen, M. A. (2016). Counter-hegemonic practices; dynamic interplay between agonism, commoning and strategic design. Strategic Design Research Journal, 9(2), 89-99. https://doi.org/10.4013/sdrj.2016.92.04

Hörger, A. C., Fones, H. N., \& Preston, G. M. (2013). The current status of the elemental defense hypothesis in relation to pathogens. Frontiers in Plant Science, 4(October), 395. https://doi.org/10.3389/fpls.2013.00395

Jones, Owain, \& Cloke, P. (2002). Tree Cultures: The Place of Trees and Trees in Their Place. Berg Publishers.

Jones, Owain, \& Cloke, P. (2008). Non-Human Agencies: Trees in Place and Time. In Material Agency. Towards a Non_Anthropocentric Approach (pp. 79-96). https://doi.org/10.1007/978-0-38774711-8

Kirksey, E., Schuetze, C., \& Helmreich, S. (2014). Tactics of Multispecies Ethnography. In The Multispecies Salon (pp. 1-24). https://doi.org/10.1215/9780822376989

Rice, L. (2017). Nonhumans in participatory design. CoDesign, 0882(October), 1-20. https://doi.org/10.1080/15710882.2017.1316409

Sauerbeck, D. (1991). Plant, element and soil properties governing uptake and availability of heavy metals derived from sewage sludge. Water Air and Soil Pollution, 57(8), 227-237.

Souza, L. A., Piotto, F. A., Nogueirol, R. C., \& Azevedo, R. A. (2013). Use of non-hyperaccumulator plant species for the phytoextraction of heavy metals using chelating agents. Scientia Agricola, 70(4), 290-295. https://doi.org/10.1590/S0103-90162013000400010

Wageningen University \& Research. (2018). Creative Innovation: Art Meets Science. 
https://www.wur.nl/en/article/Creative-Innovation-Art-Meets-Science-1.htm

Zerbi, G., \& Marchiol, L. (2004). Fitoestrazione di Metalli Pesanti. Editrice Universitaria Udinese.

\section{Author Bios:}

Author 1 Gionata Gatto (PhD) is an Assistant Professor at Dubai Institute of Design and Innovation and founder of Studio Gionata Gatto, a design practice based in Rotterdam (NL). Winding between different disciplines, his research exploits participatory and speculative design methods.

Author 2 Alessia Cadamuro (PhD) is a designer and scholar who focuses on participatory and situated design approaches, mediated by non-normative modes of interaction. Her current work touches relevant design issues, which are addressed from an ethical and socio-political perspective.

Acknowledgements: we would like to thank the University of Wageningen, which kindly offered us the opportunity of spending three months in different science lab to develop the project described in this work. A particular thanks goes to environmental scientist Dr. Milena Holmgren, who provided precious support for developing the preliminary research and following workshops during the residency; 